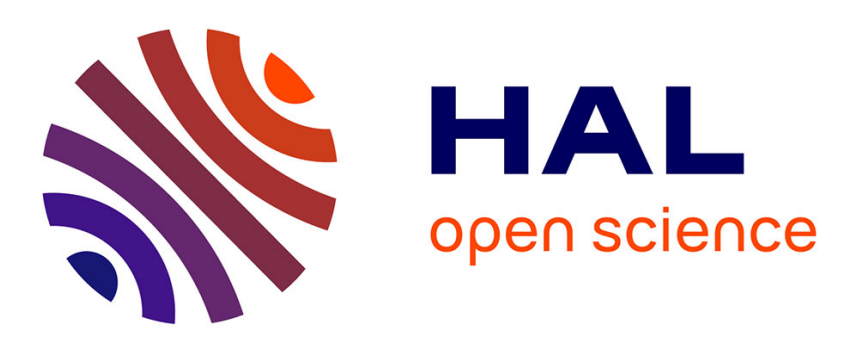

\title{
Inhibition of organic cation transporter 3 activity by tyrosine kinase inhibitors
}

Karima Alim, Amélie Moreau, Arnaud Bruyère, Elodie Jouan, Claire Denizot, Anne T Nies, Yannick Parmentier, Olivier Fardel

\section{- To cite this version:}

Karima Alim, Amélie Moreau, Arnaud Bruyère, Elodie Jouan, Claire Denizot, et al.. Inhibition of organic cation transporter 3 activity by tyrosine kinase inhibitors. Fundamental \& Clinical Pharmacology, 2021, 10.1111/fcp.12657 . hal-03134613

\section{HAL Id: hal-03134613 https://hal.science/hal-03134613}

Submitted on 19 Feb 2021

HAL is a multi-disciplinary open access archive for the deposit and dissemination of scientific research documents, whether they are published or not. The documents may come from teaching and research institutions in France or abroad, or from public or private research centers.
L'archive ouverte pluridisciplinaire HAL, est destinée au dépôt et à la diffusion de documents scientifiques de niveau recherche, publiés ou non, émanant des établissements d'enseignement et de recherche français ou étrangers, des laboratoires publics ou privés. 
PROF. ANNE NIES (Orcid ID : 0000-0001-6862-0730)

DR. OLIVIER FARDEL (Orcid ID : 0000-0001-5657-4255)

Article type : Original Article

\section{Inhibition of organic cation transporter 3 activity by tyrosine kinase inhibitors}

Running title: OCT3 inhibition by tyrosine kinases inhibitors

Karima Alima ${ }^{\mathbf{a}}$, Amélie Moreau ${ }^{\mathbf{b}}$, Arnaud Bruyère ${ }^{\mathbf{a}}$, Elodie Jouan ${ }^{\mathbf{a}}$, Claire Denizot ${ }^{\mathbf{b}}$, Anne T. Nies ${ }^{\mathbf{c}, \mathbf{d}}$, Yannick Parmentier ${ }^{\mathbf{b}}$, Olivier Fardel $\mathrm{e}^{\mathrm{e}, *}$

aUniv Rennes, Inserm, EHESP, Irset (Institut de recherche en santé, environnement et travail) UMR_S 1085, 35000 Rennes, France

${ }^{b}$ Centre de Pharmacocinétique, Technologie Servier, 45000 Orléans, France

cDr. Margarete Fischer-Bosch Institute of Clinical Pharmacology, Stuttgart and University of Tuebingen, Stuttgart 70376, Germany

${ }^{\mathrm{d}}$ Cluster of Excellence iFIT (EXC2180) "Image-Guided and Functionally Instructed Tumor Therapies", University of Tuebingen, Tuebingen, Germany 
eUniv Rennes, CHU Rennes, Inserm, EHESP, Irset (Institut de recherche en santé, environnement et travail) - UMR_S 1085, 35000 Rennes, France

*Corresponding author: Olivier Fardel, Irset-UMR_S 1085, Rennes. E-mail: olivier.fardel@univrennes1.fr 


\section{ABSTRACT}

Organic cation transporter (OCT) 3 (SLC22A3) is a widely-expressed drug transporter, handling notably metformin and platinum derivatives, as well as endogenous compounds like monoamine neurotransmitters. OCT3 has been shown to be inhibited by a few marketed tyrosine kinase inhibitors (TKIs). The present study was designed to determine whether additional TKIs may interact with OCT3. For this purpose, the effects of 25 TKIs towards OCT3 activity were analyzed using OCT3-overexpressing HEK293 cells. 13/25 TKIs, each used at $10 \mu \mathrm{M}$, were found to behave as moderate or strong inhibitors of OCT3 activity, i.e., they decreased OCT3-mediated uptake of the fluorescent dye 4-(4-(dimethylamino)styryl)-N-methylpyridinium iodide by at least $50 \%$ or $80 \%$, respectively. This OCT3 inhibition was correlated to some molecular descriptors of TKIs, such as the percentage of $\mathrm{H}$ atoms and that of cationic forms at $\mathrm{pH}=7.4$. It was concentration-dependent, notably for brigatinib, ceritinib and crizotinib, which exhibited low half maximal inhibitory concentration $\left(\mathrm{IC}_{50}\right)$ values in the $28-106 \mathrm{nM}$ range. Clinical concentrations of these three marketed TKIs, as well as those of pacritinib, were next predicted to inhibit in vivo OCT3 activity according to regulatory criteria. Cellular TKI accumulation experiments as well as trans-stimulation assays however demonstrated that OCT3 does not transport brigatinib, ceritinib, crizotinib and pacritinib, thus discarding any implication of OCT3 in the pharmacokinetics of these TKIs. Taken together, these data suggest that some TKIs may act as potent inhibitors of OCT3 activity, which may have consequences in terms of drug-drug interactions and toxicity.

Keywords: Drug-drug interaction, molecular descriptors, organic cation transporter, pharmacokinetics, tyrosine kinase inhibitor.

\section{LIST OF ABBREVIATIONS}

ALK, anaplastic lymphoma kinase;

ALOGP, Ghose-Crippen octanol-water partition;

DDI, drug-drug interaction;

DiASP, 4-(4-(dimethylamino)styryl)-N-methylpyridiniumiodide; 
EGFR, epidermal growth factor receptor;

EMT, extraneuronal monoamine transporter;

FAU, fluorescence arbitrary unit;

FDA, Food and Drug Administration;

Flt3, Fms-like tyrosine kinase 3;

$\mathrm{IC}_{50}$, half maximal inhibitory concentration;

JAK, Janus kinase;

LC-MS/MS, liquid chromatography-tandem mass spectrometry;

MATE, multidrug and toxin extrusion protein;

MLOGP, Moriguchi octanol-water partition coefficient;

$\mathrm{MPP}^{+}$, 1-methyl-4-phenylpyridinium;

OCT, organic cation transporter; PBS, phosphate-buffered saline;

TKI, tyrosine kinase inhibitor;

TPSA, topological polar surface area. 


\section{INTRODUCTION}

Organic cation transporter (OCT) 3 (SLC22A3, also known as the extraneuronal monoamine transporter (EMT)), is a membrane drug transporter belonging to the solute carrier (SLC) family [1]. OCT3 handles various drugs, including cisplatin, metformin and quinidine, as well as endogenous compounds like neurotransmitters, histamine and creatinine [2-5]. Many of its substrates are shared with the two other OCTs, i.e., OCT1 and OCT2. OCT3, unlike OCT1 and OCT2, is rather widely expressed [6]. OCT3 is notably found in tissues relevant for pharmacokinetics, such as the liver and kidney [7], where it is localized at the sinusoidal membrane of hepatocytes and the basolateral membrane of renal proximal tubule epithelial cells, respectively [8]. The transporter is also present at the luminal membrane of small intestinal enterocytes, where it contributes to oral absorption of metformin [9]. OCT3 is additionally found in the heart and may consequently play a role in cardiac tissue drug exposure [10], as well as in the placenta, where it facilitates foetal exposure to metformin during pregnancy [11]. Taken together, these data suggest that OCT3 may be a drug transporter to consider according to a pharmacokinetical, pharmacological and/or toxicological point of view, even if it is presently not included in the list of drug transporters that have to be studied during the development of new molecular entities according to regulatory authorities for drug approval in the US and Europe [12, $13]$.

Various drugs block OCT3 activity and may consequently theoretically cause drug-drug interactions (DDIs) and/or OCT3 inhibition-related adverse effects [8]. In particular, some tyrosine kinase inhibitors (TKIs), like the Bcr-Abl inhibitors imatinib, dasatinib and nilotinib, the epidermal growth factor receptor (EGFR) inhibitors gefitinib and erlotinib, and the multi-kinase inhibitors sunitinib and sorafenib, inhibit in vitro OCT3 activity, at concentrations thought to be reached in vivo for at least nilotinib, thus supporting a potential clinical relevance of these effects [14]. Whether other TKIs can also behave as inhibitors and/or substrates for OCT3 is however unknown, but likely deserves interest owing to the current development of TKIs as a leading pharmacological class for various therapeutic indications, to the role that transporters play in TKI pharmacokinetics and activity $[15,16]$ and to the fact that some TKIs like abemaciclib have been clinically shown to increase exposure to the OCT3 substrate metformin [17]. To get insights about 
this point in the present study, we have analyzed the interactions of OCT3 with 25 TKIs, targeting various tyrosine kinases and regulatory-approved $(n=23)$ or under clinical development $(n=2)$.

\section{MATERIAL AND METHODS}

\section{Chemicals}

The 23 marketed TKIs abemaciclib, acalabrutinib, afatinib, alectinib, brigatinib, cabozantinib, ceritinib, crizotinib, dacomitinib, entrectinib, ibrutinib, lapatinib, lenvatinib, lorlatinib, neratinib, nintedanib, osimertinib, ponatinib, regorafenib, ribociclib, ruxolitinib, tofacitinib and vemurafenib as well as itacitinib and pacritinib, 2 TKIs under clinical phase 3 development, were provided by MedChemtronica (Sollentuna, Sweden). These TKIs target various kinases, as indicated in Table 1. Corticosterone and unlabeled 1-methyl-4-phenylpyridinium $\left(\mathrm{MPP}^{+}\right)$were from Sigma-Aldrich (Saint Quentin Fallavier, France) and 4-(4-(dimethylamino)styryl)-N-methylpyridiniumiodide (DiASP) from Thermo Fisher Scientific (Waltham, MA, USA). N-[methyl- $\left.{ }^{3} \mathrm{H}\right]-\mathrm{MPP}^{+}$(specific activity $=81.8 \mathrm{mCi} / \mathrm{mmol}$ ) was purchased from PerkinElmer (Villebon-sur-Yvette, France).

\section{Cell culture}

HEK293 cells overexpressing OCT3 (HEK-OCT3 cells) as well as control HEK293-MOCK cells (HEK-CTR cells), obtained by stable transfection [18], were cultured in DMEM medium, supplemented with $10 \%$ (vol/vol) fetal calf serum, $1 \mu \mathrm{g} / \mathrm{mL}$ bovine insulin, $1 \%$ (vol/vol) nonessential amino acid solution, $800 \mu \mathrm{g} / \mathrm{mL} \mathrm{G} 418,20 \mathrm{UI} / \mathrm{mL}$ penicillin and $20 \mu \mathrm{g} / \mathrm{mL}$ streptomycin.

\section{OCT3 activity inhibition assay}

Inhibition of cellular OCT3 activity was investigated using the fluorescent OCT probe DiASP, which is transported into HEK-OCT3 cells in a saturable manner $\left(\mathrm{K}_{\mathrm{m}}=24.8 \pm 5.1 \mu \mathrm{M}\right)$ [19]. Briefly, cells were incubated with $10 \mu \mathrm{M}$ DiASP for $5 \mathrm{~min}$ at $37^{\circ} \mathrm{C}$, in the absence or presence of the reference OCT3 inhibitor corticosterone or of TKIs, in the transport assay medium previously described [20]. After washing with phosphate-buffered saline (PBS), intracellular accumulation of the dye was determined by spectrofluorimetry, using a SpectraMax Gemini SX spectrofluorometer 
(Molecular Devices, Sunnyvale, CA, USA); excitation and emission wavelengths were $485 \mathrm{~nm}$ and $607 \mathrm{~nm}$, respectively. Data were finally normalized to total protein content, determined by the Bradford's method [21]. They were expressed as fluorescence arbitrary unit (FAU)/mg protein or as percentages of OCT3 activity or of OCT3 activity inhibition according to the equation (A) or (B), respectively:

$$
\begin{gathered}
\% \text { OCT3 activity }=\frac{\left(\left[\text { DiASP }_{\text {TKI }}\right]-\left[\text { DiASP }_{\text {Corticosterone }}\right]\right) \times 100}{\left(\left[\text { DiASP }_{\text {Control }}\right]-\left[\text { DiASP }_{\text {Corticosterone }}\right]\right)} \\
\% \text { OCT3 activity inhibition }=100 \%-\% \text { OCT3 activity }
\end{gathered}
$$

with $\left[\mathrm{DiASP}_{\mathrm{TKI}}\right]=$ DiASP concentration in the presence of a defined concentration of TKI, $\left[\mathrm{DiASP}_{\text {Corticosterone }}\right]=$ DiASP concentration in the presence of $100 \mu \mathrm{M}$ corticosterone and $\left[\right.$ DiASP $\left._{\text {Control }}\right]=$ DiASP concentration in control cells not exposed to TKI or corticosterone.

Half maximal inhibitory concentration $\left(\mathrm{IC}_{50}\right)$ for TKIs towards OCT3 activity was calculated using Prism 8.4.2 software (GraphPad Software, La Jolla, CA, USA), through nonlinear regression based on the following four-parameter logistic equation:

$$
A=\frac{100}{1+10^{([I]-\log (\mathrm{IC} 50)) \times \text { Hill slope }}}
$$

with $\mathrm{A}=$ percentage of transporter activity for a given concentration of TKI determined as described in equation (A), [I] is the TKI concentration in the medium, and Hill slope is a coefficient describing the steepness of the curve.

\section{Reversibility of OCT3 activity inhibition by TKIs}

HEK-OCT3 cells were first incubated in the absence (control) or presence of $10 \mu \mathrm{M}$ TKIs for 5 min at $37^{\circ} \mathrm{C}$. After washing, cells were either used directly for OCT3 activity measurement, performed as described above, or were re-incubated in TKI-free medium for $3 \mathrm{~h}$ before OCT3 activity measurement. Data were finally expressed as percentages of OCT3 activity inhibition.

\section{Prediction of in vivo inhibition of OCT3 by TKIs}

From in vitro $\mathrm{IC}_{50}$ values, in vivo inhibition of OCT3 activity by TKIs was predicted through applying the criteria defined by the US Food and Drug Administration (FDA) guidance on in vitro drug interaction studies [12] to OCT3, i.e., a transporter-related DDI can be expected if : 


$$
\text { IC50 } / \text { Imax, u }>0.1
$$

with $\mathrm{I}_{\mathrm{max}, \mathrm{u}}=$ maximum unbound plasma concentration of the TKI.

\section{Trans-stimulation assay}

Trans-stimulation assays were performed in HEK-OCT3 cells using the OCT3 substrate MPP ${ }^{+}$ [22]; such trans-stimulation assays for OCTs are based on the fact that substrates of these transporters can both cis-inhibit and trans-stimulate them [23]. Briefly, HEK-OCT3 cells were first incubated with $1 \mathrm{mM}$ unlabeled $\mathrm{MPP}^{+}$or $30 \mu \mathrm{M}$ TKI for $30 \mathrm{~min}$ at $37^{\circ} \mathrm{C}$. After washing with PBS, cells were next re-incubated with radiolabeled $\left[{ }^{3} \mathrm{H}\right]-\mathrm{MPP}^{+}$(used at $6.0 \mathrm{nM}$ ) for 5 min at $37^{\circ} \mathrm{C}$. Intracellular accumulation of radiolabeled $\mathrm{MPP}^{+}$was next determined by liquid scintillation counting using a Tri-Carb 4810TR counter (Perkin-Elmer), after addition of $2 \mathrm{ml} / \mathrm{sample}$ of the liquid scintillation cocktail Ultima Gold ${ }^{\mathrm{TM}}$ (Perkin Elmer). Data were normalized to protein content and finally expressed as percentages of $\left[{ }^{3} \mathrm{H}\right]-\mathrm{MPP}^{+}$accumulation found in control cells not pre-treated by unlabeled MPP ${ }^{+}$or TKIs.

\section{TKI accumulation assay}

HEK-CTR and HEK-OCT3 cells were incubated with $10 \mu \mathrm{M}$ TKI, in the absence or presence of $100 \mu \mathrm{M}$ corticosterone, for $5 \mathrm{~min}$ at $37^{\circ} \mathrm{C}$. Cells were then washed twice in ice-cold PBS, lysed in distilled water and acetonitrile-based extraction of cell lysates was performed. TKI quantification was next performed through liquid chromatography-tandem mass spectrometry (LC-MS/MS), based on a high-performance liquid chromatography Aria system (Agilent, Les Ulis, France), equipped with a Poroshell $120 \mathrm{C} 18(4.6 \times 100 \mathrm{~mm})$ column (Agilent, Les Ulis, France) and coupled to a tandem mass spectrometry TSQ Quantum (Thermo Fisher Scientific, Villebon sur Yvette, France), fitted with an electrospray ionization source (ESI+). Monitored ion transitions were at $466.1>372.1 \mathrm{~m} / \mathrm{z}$ (for acalabrutinib), $584.0>484.2 \mathrm{~m} / \mathrm{z}$ (for brigatinib), 558.0 $>433.0$ (for ceritinib), 449.9>260.1 (for crizotinib) and 437.1>316.1 (for pacritinib). Data were finally normalized to protein content.

\section{TKI molecular descriptor generation}


83 molecular descriptors belonging to the blocks "constitutional indices" $(n=47)$, "charge descriptors" $(n=15)$ and "molecular properties" $(n=20)$, were determined using the Dragon 7.0 software (Talete, Milano, Italy) (See http://www.talete.mi.it/products/dragon_molecular_descriptor_list.pdf for a complete list of these descriptors). TKIs, initially expressed in SMILES format, were converted to 3D format using MarvinView 20.19.0 software (ChemAxon, Budapest, Hungary) before processing by Dragon 7.0 software to obtain molecular descriptors, as previously described [19]. An additional charge descriptor, i.e., the percentage of cationic form of TKIs at $\mathrm{pH}=7.4$, was determined using MarvinSketch 20.19.0 software; the total number of molecular descriptors analyzed for each TKI was therefore 84 .

\section{Statistical analysis}

Experimental data were routinely expressed as means $\pm \mathrm{SD}$ of at least three independent assays, each being usually performed in triplicate. Normality distribution of percentages of OCT3 activity inhibition by TKIs was checked by D'Agostino and Pearson omnibus normality test. Data were statistically analyzed through analysis of variance (ANOVA) followed by the Dunnett's or Tukey's post-hoc test. Correlation between molecular descriptor indexes and percentages of OCT3 activity inhibition by TKIs was performed through Pearson correlation. The criterion of significance was $\mathrm{p}<0.05$. All the statistical analyses were done using Prism 8.4.2 software.

\section{RESULTS}

\section{Inhibition of in vitro OCT3 activity by TKIs}

The effects of $10 \mu \mathrm{M}$ TKIs towards OCT3-mediated transporter of DiASP were investigated in HEK-OCT3 cells. As shown in Table 1, 5/25 TKIs, i.e., alectinib, cabozantinib, itacitinib, lapatinib and vemurafenib, failed to significantly alter OCT3 activity. Among the 20/25 TKIs which inhibited OCT3, some of them (7/25 TKIs), i.e., lorlatinib, neratinib, nintedanib, osimertinib, regoferanib, ruxolitinib and tofacitinib, decreased OCT3 activity by less than 50\% and can thus be considered as weak OCT3 inhibitors. Other TKIs (8/25 TKIs), i.e., abemaciclib, afatinib, dacomitinib, entrectinib, ibrutinib, lenvatinib, ponatinib and ribociclib, were found to 
inhibit OCT 3 activity by more than $50 \%$ but less than $80 \%$ (Table 1 ) and thus appear as moderate inhibitors of the transporter. 5/25 TKIs, i.e., acalabrutinib, brigatinib, ceritinib, crizotinib and pacritinib were found to inhibit OCT3 by more than $80 \%$ (Table 1) and are consequently potent inhibitors of OCT3 activity. These five strong OCT3 inhibitors were next found to inhibit OCT3 in a concentration-dependent manner, with $\mathrm{IC}_{50}$ values ranging from $28.2 \mathrm{nM}$ (for ceritinib) to 1841 nM (for acalabrutinib) (Figure 1). We next investigated whether TKI-mediated inhibition of OCT3 may be reversible. For this purpose, cells were initially exposed to $10 \mu \mathrm{M}$ TKI for $5 \mathrm{~min}$, washed and re-incubated in TKI-free medium for $3 \mathrm{~h}$ before measurement of OCT3 activity. As indicated in Figure 2, inhibition of OCT3 activity by acalabrutinib was fully suppressed by the $3 \mathrm{~h}$ TKI-free post-incubation period, whereas those due to brigatinib or pacritinib were partly reversed. This indicates that the inhibitory effects of these TKIs towards OCT3 were fully (acalabrutinib) or partly (brigatinib and pacritinib) reversible after a $3 \mathrm{~h}$ TKI-free post-incubation period. By contrast, inhibition of OCT3-mediated transport by ceritinib and crizotinib was not significantly impaired by a $3 \mathrm{~h}$ TKI-free post-incubation when compared to the control condition without a TKI-free post-incubation (Figure 2).

In order to investigate physico-chemical structural requirements for OCT3 inhibition by

TKIs, percentages of inhibition of OCT3 activity by the 25 TKIs (each used at $10 \mu \mathrm{M}$ ) were next confronted to values of 84 TKI molecular descriptors, through Pearson correlation analysis. 7/84 molecular descriptors were found to be significantly either positively $(n=2)$ or negatively $(n=5)$ correlated with OCT3 inhibition (Table 2). This notably concerns the percentage of $\mathrm{H}$ atoms ( $\mathrm{H} \%)$ and the percentage of cationic forms. The 77/84 molecular descriptors not correlated with OCT3 activity inhibition, including lipophilicity-related parameters such as Moriguchi octanol-water partition coefficient (MLOGP) and Ghose-Crippen octanol-water partition (ALOGP) as well as topological polar surface area (TPSA), are listed in Table S1.

\section{Prediction of in vivo OCT3 inhibition by TKIs}

The prediction of in vivo OCT3 inhibition was performed for TKIs defined above as strong inhibitors, i.e., acalabrutinib, brigatinib, ceritinib, crizotinib and pacritinib. It was done using the criteria defined by the U.S. FDA and based on the ratio $\mathrm{IC}_{50} / \mathrm{I}_{\max , \mathrm{u}}$. As indicated in Table 3, brigatinib, ceritinib, crizotinib and pacritinib, unlike acalabrutinib, were predicted to inhibit in vivo OCT3 activity at clinically achievable concentrations. 


\section{Transport of TKIs by OCT3}

To determine whether TKIs potently interacting with OCT3 activity, i.e., acalabrutinib, brigatinib, ceritinib, crizotinib and pacritinib, may be subtrates for OCT3, trans-stimulation assays were performed, because substrates for OCTs, including OCT3, are postulated to trans-stimulate OCT activities [22, 23]. As shown in Figure 3, acalabrutinib, brigatinib, ceritinib, crizotinib and pacritinib failed to trans-stimulate OCT3-mediated radiolabeled $\mathrm{MPP}^{+}$accumulation in HEKOCT3 cells. By contrast, unlabeled $\mathrm{MPP}^{+}$trans-stimulated OCT3 activity (by a 4.7-fold-factor) (Figure 3). Intracellular accumulation of TKIs was next determined in HEK-CTR and HEK-OCT3 cells by LC-MS/MS assay, in the absence or presence of the OCT3 inhibitor corticosterone. As shown in Figure 4, accumulations in HEK-CTR and HEK-OCT3 cells were similar for each analyzed TKI and corticosterone failed to reduce TKI concentrations in HEK-OCT3 cells. By contrast, accumulation of the reference OCT3 substrate DiASP was significantly increased in HEK-OCT3 cells when compared to HEK-CTR cells (by a 4.2-fold factor). This enhanced accumulation of DiASP in HEK-OCT3 cells was nevertheless markedly reduced in the presence of corticosterone (Figure 4).

\section{DISCUSSION}

The data of the present study fully confirm that TKIs can interact with OCT3 activity. Indeed, only 5/25 TKIs were devoid of any inhibitory effect towards OCT3 activity, whereas 13/25 TKIs were characterized as moderate or strong inhibitors of OCT3 and 7/25 TKIs as weak inhibitors. TKIs acting as moderate and strong inhibitors block more than $50 \%$ of OCT 3 activity when used at 10 $\mu \mathrm{M}$, thus supporting the conclusion that their $\mathrm{IC}_{50}$ values towards OCT3 are less than $10 \mu \mathrm{M}$. Such compounds can therefore be unambiguously added to the list of TKIs blocking OCT3, which already comprises 6 other TKIs, including imatinib, nilotinib and erlotinib [14]. The kinases targeted by these TKIs blocking OCT3 activity are diverse, including the anaplastic lymphoma kinase (ALK) inhibited by brigatinib, ceritinib and crizotinib, the Janus kinase (JAK) 2 and the Fms-like tyrosine kinase 3 (Flt3) inhibited by pacritinib, the kinase Bcr-Abl inhibited by imatinib and nilotinib and the EGFR inhibited by erlotinib. Inhibition of OCT3 activity by TKIs is therefore not linked to the targeting of a specific tyrosine kinase. For some strong inhibitors of OCT3 such 
as brigatinib, ceritinib and crizotinib, $\mathrm{IC}_{50}$ values are comprised in the $28-106 \mathrm{nM}$ range, whereas $\mathrm{IC}_{50}$ values for OCT3 inhibitors are commonly in the 1-100 $\mu \mathrm{M}$ range [18, 24-27]; this illustrates the rather potent in vitro inhibitory effect of these TKIs towards OCT3, similar to that of reference OCT3 inhibitors such as corticosterone or decynium 22, for which $\mathrm{IC}_{50}$ values are in the 100-300 $\mathrm{nM}$ range [28]. Moreover, the inhibition of OCT3 activity by $10 \mu \mathrm{M}$ ceritinib or $10 \mu \mathrm{M}$ crizotinib was not impaired by a $3 \mathrm{~h}$ TKI-free post-incubation period, suggesting a long-lasting action of these two TKIs. Beyond OCT3, other SLCs handling organic cations such as OCT1, OCT2, multidrug and toxin extrusion protein (MATE) 1 and MATE2-K have been shown to be inhibited by various TKIs [14], thus indicating that transporters of organic cations may represent privileged targets of TKIs. In this context, it is noteworthy that one TKI may inhibit multiple SLCs transporting organic cations. As an example, in addition to OCT3, the transporters OCT1, MATE1 and MATE2-K are inhibited by brigatinib [29], whereas clinically relevant concentrations of crizotinib block OCT1 and OCT2 activities [30], therefore supporting the hypothesis that these TKIs may act as powerful inhibitors of organic cation transport.

Among the five strong OCT3 inhibitors reported in the present study, 4, i.e., the ALK inhibitors brigatinib, ceritinib and crizotinib as well as the JAK2/Flt3 inhibitor pacritinib are predicted to in vivo inhibit OCT3 according to the criteria defined by the U.S. FDA. This point may merit consideration in terms of possible DDIs and/or adverse effects. Indeed, even if OCT3 is presently not considered as a priority transporter by drug agencies, it is present at various sites implicated in pharmacokinetics and handles various marketed drugs. It is notably the case for metformin, for which OCT3 is involved in pharmacokinetics and pharmacological response in humans [31-33]. OCT3 may notably be implicated in intestinal absorption of metformin [9], as well as in fetal exposure to this hypoglycemic agent [11]; it may also govern its antiproliferative effects in OCT3-expressing cancer cells [34, 35]. TKIs inhibiting in vivo OCT3 activity may therefore be suspected to alter pharmacokinetics and/or pharmacological activity of metformin. Further studies are likely required to investigate these points. The possible inhibition by TKIs of the OCT3-mediated transport of endogenous compounds, like monoamine neurotransmitters, histamine or creatinine, and its clinical consequences may also deserve interest. This likely concerns the placental OCT3, known to be an essential component of foeto-placental homeostasis of serotonin [36].

Various molecular descriptors have been associated with inhibition of SLC transporter activities, notably for OCTs and MATEs [24, 37, 38]. Inhibition of OCT3 by heterocyclic 
aromatic amines is thus positively correlated with percentage of cationic form at $\mathrm{pH}=7.4$ and percentage of $\mathrm{H}$ atoms [19]. Such molecular descriptors are similarly correlated with OCT3 inhibition by TKIs (Table 1), thus supporting the idea that they correspond to robust molecular descriptors to be considered for OCT3 inhibition. Cationic positive fraction at $\mathrm{pH}=7.4$ has also a high value for OCT1, OCT2 or MATE1 inhibition [24, 37, 38], therefore suggesting that this descriptor is a key-parameter associated with impairment of OCT/MATE activities by drugs. By contrast, parameters such as lipophilicity $(\log P)$ or TPSA are correlated with inhibition of OCT1 and OCT2, but not with blockage of OCT3 by heterocyclic aromatic amines [19] or by TKIs [14] (Table S1). This lack of contribution of lipophilicity to OCT3 inhibition however likely merits complementary investigations because it is challenged by the enhanced inhibitory potency of phenylguanidines with increased lipophilic character towards OCT3 activity [39]. Excessive lipophilicity may nevertheless make it difficult for a TKI to access the substrate binding region of OCT3 in contact with the aqueous phase, as already proposed for OCT1 [14].

Acalabrutinib, brigatinib, ceritinib, crizotinib and pacritinib failed to trans-stimulate OCT3 activity, in contrast to the reference substrate $\mathrm{MPP}^{+}$. Moreover, similar accumulation of these TKIs were found in HEK-CTR and HEK-OCT3 cells, without impairment by the OCT3 inhibitor corticosterone. Taken together, these data suggest that these TKIs are not substrates for OCT3. OCT3 is therefore unlikely to play a major role in their pharmacokinetic properties. In the same way, the TKI imatinib blocks OCT3, but is not handled by this transporter [14, 40]. Such data consequently suggest that TKIs likely interact with OCT3 through cis-inhibiting its activity, without being transported.

In summary, various TKIs (13/25) were demonstrated to behave as moderate or strong inhibitors of OCT3. For some of them like brigatinib, ceritinib, crizotinib and pacritinib, realistic clinical concentrations were predicted to in vivo inhibit OCT3 activity, which may have consequences in terms of DDIs or toxicity. OCT3 may therefore appear as a drug transporter worthy of interest when considering the use of TKIs. 


\section{ACKNOWLEDGMENTS}

A.T. Nies was in part funded by the Robert Bosch Stiftung (Stuttgart, Germany) and the Deutsche Forschungsgemeinschaft (DFG, German Research Foundation) under Germany's Excellence Strategy - EXC $2180-390900677$. 


\section{REFERENCES}

[1] Koepsell H. Organic Cation Transporters in Health and Disease. Pharmacol. Rev. (2020) 72 253-319.

[2] Wagner D.J., Hu T., Wang J. Polyspecific organic cation transporters and their impact on drug intracellular levels and pharmacodynamics. Pharmacol. Res. (2016) 111 237-246.

[3] Wu X., Kekuda R., Huang W., Fei Y.J., Leibach F.H., Chen J. et al. Identity of the organic cation transporter OCT3 as the extraneuronal monoamine transporter (uptake2) and evidence for the expression of the transporter in the brain. J. Biol. Chem. (1998) 273 32776-32786.

[4] Nakada T., Kudo T., Kume T., Kusuhara H., Ito K. Estimation of changes in serum creatinine and creatinine clearance caused by renal transporter inhibition in healthy subjects. Drug Metab. Pharmacokinet. (2019) 34 233-238.

[5] Schneider E., Machavoine F., Pléau J.M., Bertron A.F., Thurmond R.L., Ohtsu H. et al. Organic cation transporter 3 modulates murine basophil functions by controlling intracellular histamine levels. J. Exp. Med. (2005) 202 387-393.

[6] Nies A.T., Koepsell H., Damme K., Schwab M. Organic cation transporters (OCTs, MATEs), in vitro and in vivo evidence for the importance in drug therapy. Handb. Exp. Pharmacol. (2011) (201) 105-167.

[7] Jonker J.W., Schinkel A.H. Pharmacological and physiological functions of the polyspecific organic cation transporters: OCT1, 2, and 3 (SLC22A1-3). J. Pharmacol. Exp. Ther. (2004) 308 2-9.

[8] Koepsell H. Role of organic cation transporters in drug-drug interaction. Expert Opin. Drug Metab. Toxicol. (2015) 11 1619-1633.

[9] Shirasaka Y., Lee N., Zha W., Wagner D., Wang J. Involvement of organic cation transporter 3 (Oct3/Slc22a3) in the bioavailability and pharmacokinetics of antidiabetic metformin in mice. Drug Metab. Pharmacokinet. (2016) 31 385-388.

[10] Solbach T.F., Grube M., Fromm M.F., Zolk O. Organic cation transporter 3: expression in failing and nonfailing human heart and functional characterization. J. Cardiovasc. Pharmacol. (2011) 58 409-417.

[11]Lee N., Hebert M.F., Wagner D.J., Easterling T.R., Liang C.J., Rice K., et al. Organic Cation Transporter 3 Facilitates Fetal Exposure to Metformin during Pregnancy. Mol. Pharmacol. (2018) 94 1125-1131. 
[12] In Vitro Drug Interaction Studies - Cytochrome P450 Enzyme- and Transporter-Mediated Drug Interactions Guidance for Industry, US Food and Drug Administration. (Cited 2020 September 8), Available from https://www.fda.gov/regulatory-information/search-fdaguidance-documents/vitro-drug-interaction-studies-cytochrome-p450-enzyme-andtransporter-mediated-drug-interactions.

[13] Sudsakorn S., Bahadduri P., Fretland J., Lu C. 2020 FDA Drug-drug Interaction Guidance: A Comparison Analysis and Action Plan by Pharmaceutical Industrial Scientists. Curr. Drug Metab. (2020) 21 403-426.

[14] Minematsu T., Giacomini K.M. Interactions of tyrosine kinase inhibitors with organic cation transporters and multidrug and toxic compound extrusion proteins. Mol. Cancer Ther. (2011) 10 531-539.

[15]Neul C., Schaeffeler E., Sparreboom A., Laufer S., Schwab M., Nies A.T. Impact of Membrane Drug Transporters on Resistance to Small-Molecule Tyrosine Kinase Inhibitors. Trends Pharmacol. Sci. (2016) 37 904-932.

[16] Garrison D.A., Talebi Z., Eisenmann E.D., Sparreboom A., Baker S.D. Role of OATP1B1 and OATP1B3 in Drug-Drug Interactions Mediated by Tyrosine Kinase Inhibitors. Pharmaceutics. (2020) 12856.

[17] Chappell J.C., Turner P.K., Pak Y.A., Bacon J., Chiang A.Y., Royalty J. et al. Abemaciclib Inhibits Renal Tubular Secretion Without Changing Glomerular Filtration Rate. Clin. Pharmacol. Ther. (2019) 105 1187-1195.

[18]Nies A.T., Hofmann U., Resch C., Schaeffeler E., Rius M., Schwab M. Proton pump inhibitors inhibit metformin uptake by organic cation transporters (OCTs). PLoS One. (2011) 6 e22163.

[19] Sayyed K., Camillerapp C., Le Vée M., Bruyère A., Nies A.T., Abdel-Razzak Z. et al. Inhibition of organic cation transporter (OCT) activities by carcinogenic heterocyclic aromatic amines. Toxicol In Vitro. (2019) 54 10-22.

[20] Moreau A., Le Vee M., Jouan E., Parmentier Y., Fardel O. Drug transporter expression in human macrophages. Fundam. Clin. Pharmacol. (2011) 25 743-752.

[21] Bradford M.M. A rapid and sensitive method for the quantitation of microgram quantities of protein utilizing the principle of protein-dye binding. Anal. Biochem. (1976) 72 248-254. 
[22] Gründemann D., Hahne C., Berkels R., Schömig E. Agmatine is efficiently transported by non-neuronal monoamine transporters extraneuronal monoamine transporter (EMT) and organic cation transporter 2 (OCT2). J. Pharmacol. Exp. Ther. (2003) 304 810-817.

[23]Zhang L., Gorset W., Dresser M.J., Giacomini K.M. The interaction of n-tetraalkylammonium compounds with a human organic cation transporter, hOCT1. J. Pharmacol. Exp. Ther. (1999) 288 1192-1198.

[24] Wittwer M.B., Zur A.A., Khuri N., Kido Y., Kosaka A., Zhang X. et al. Discovery of potent, selective multidrug and toxin extrusion transporter 1 (MATE1, SLC47A1) inhibitors through prescription drug profiling and computational modeling. J. Med. Chem. (2013) 56 781-795.

[25]Hu T., Wang L., Pan X., Qi H. Novel compound, organic cation transporter 3 detection agent and organic cation transporter 3 activity inhibitor, WO2015002150 A1: a patent evaluation. Expert Opin. Ther. Pat. (2016) 26 857-860.

[26]Li L., Sun S., Weng Y., Song F., Zhou S., Bai M. et al. Interaction of six protoberberine alkaloids with human organic cation transporters 1, 2 and 3. Xenobiotica (2016) 46 175-183.

[27]Zhu H.J., Appel D.I., Gründemann D., Richelson E., Markowitz J.S. Evaluation of organic cation transporter 3 (SLC22A3) inhibition as a potential mechanism of antidepressant action. Pharmacol. Res. (2012) 65 491-496.

[28]Hayer-Zillgen M., Brüss M., Bönisch H. Expression and pharmacological profile of the human organic cation transporters hOCT1, hOCT2 and hOCT3. Br. J. Pharmacol. (2002) 136 829-836.

[29] Brigatinib. Multi-discipline review, Center for Drug Evaluation and Research, US Food and Drug Administration (Cited 2020 October 13), Available from: https://www.accessdata.fda.gov/drugsatfda_docs/nda/2017/208772Orig1s000MultidisciplineR .pdf.

[30]Crizotinib. Label, Center for Drug Evaluation and Research, US Food and Drug Administration. (Cited 2020 October 26), Available from: https://www.accessdata.fda.gov/drugsatfda_docs/label/2018/202570s027lbl.pdf.

[31]Kwon E.Y., Chung J.Y., Park H.J., Kim B.M., Kim M., Choi J.H. OCT3 promoter haplotype is associated with metformin pharmacokinetics in Koreans. Sci Rep. (2018) 816965.

[32]Zaharenko L., Kalnina I., Geldnere K., Konrade I., Grinberga S., Židzik J. et al. Single nucleotide polymorphisms in the intergenic region between metformin transporter OCT2 and 
OCT3 coding genes are associated with short-term response to metformin monotherapy in type 2 diabetes mellitus patients. Eur. J. Endocrinol. (2016) 175 531-540.

[33] Hosseyni-Talei S.R., Mahrooz A., Hashemi-Soteh M.B., Ghaffari-Cherati M. \& Alizadeh A. Association between the synonymous variant organic cation transporter 3 (OCT3)-1233G $>A$ and the glycemic response following metformin therapy in patients with type 2 diabetes. Iran. J. Basic Med. Sci. (2017) 20 250-255.

[34]Cai H., Zhang Y., Han T.K., Everett R.S., Thakker D.R. Cation-selective transporters are critical to the AMPK-mediated antiproliferative effects of metformin in human breast cancer cells. Int. J. Cancer. (2016) 138 2281-2292.

[35] Cai H., Everett R.S., Thakker D.R. Efficacious dose of metformin for breast cancer therapy is determined by cation transporter expression in tumours. Br. J. Pharmacol. (2019) 176 27242735.

[36] Karahoda R., Horackova H., Kastner P., Matthios A., Cerveny L., Kucera R. et al. Serotonin homeostasis in the materno-foetal interface at term: Role of transporters (SERT/SLC6A4 and OCT3/SLC22A3) and monoamine oxidase A (MAO-A) in uptake and degradation of serotonin by human and rat term placenta. Acta Physiol. (Oxf). (2020) 229 e13478.

[37] Ahlin G., Karlsson J., Pedersen J.M., Gustavsson L., Larsson R., Matsson P. et al. Structural requirements for drug inhibition of the liver specific human organic cation transport protein 1 . J. Med. Chem. (2008) 51 5932-5942.

[38] Kido Y., Matsson P., Giacomini K.M. Profiling of a prescription drug library for potential renal drug-drug interactions mediated by the organic cation transporter 2. J. Med. Chem. (2011) 54 4548-4558.

[39] Pan X., Iyer K.A., Liu H., Sweet D.H., Dukat M. A new chemotype inhibitor for the human organic cation transporter 3 (hOCT3). Bioorg. Med. Chem. Lett. (2017) 27 4440-4445.

[40] Blanc Mettral J., Faller N., Cruchon S., Sottas L., Buclin T., Schild L. et al. Imatinib Uptake into Cells is Not Mediated by Organic Cation Transporters OCT1, OCT2, or OCT3, But is Influenced by Extracellular pH. Drug Metab. Lett. (2019) 13 102-110.

[41] Acalabrutinib. Review, Center for Drug Evaluation and Research, US Food and Drug Administration (Cited 2020 October 13), Available from: https://www.accessdata.fda.gov/drugsatfda_docs/nda/2019/210259Orig1s006,\%20s007.pdf. 
[42] Ceritinib. Pharmacology review, Center for Drug Evaluation and Research, US Food and Drug Administration. (Cited 2020 October 13), Available from: https://www.accessdata.fda.gov/drugsatfda_docs/nda/2014/205755Orig1s000PharmR.pdf.

[43] Crizotinib. Pharmacology review, Center for Drug Evaluation and Research, US Food and Drug Administration (Cited 2020 October 13), Available from: https://www.accessdata.fda.gov/drugsatfda_docs/nda/2011/202570Orig1s000PharmR.pdf.

[44] Pacritinib. Assessment report, European Medecines Agency (Cited 2020 October 13), Available from: https://www.ema.europa.eu/en/documents/withdrawal-report/withdrawal-assessmentreport-enpaxiq_en.pdf. 


\section{LEGENDS TO FIGURES}

Figure 1. Concentration-dependent inhibition of OCT3 activity by TKIs.

HEK-OCT3 cells were incubated with $10 \mu \mathrm{M}$ DiASP for $5 \mathrm{~min}$ at $37{ }^{\circ} \mathrm{C}$, in the absence or presence of various concentrations of TKIs (from $1 \mathrm{nM}$ to $30 \mu \mathrm{M}$ ) or of $100 \mu \mathrm{M}$ corticosterone, used here as a reference OCT3 inhibitor. After washing with PBS, intracellular accumulation of DiASP was determined by spectrofluorimetry and normalized to protein content. Data are expressed as percentages of OCT3 activity found in control cells exposed only to DiASP, arbitrarily set at $100 \%$; they are the means \pm SD of at least three independent experiments. TKI $\mathrm{IC}_{50}$ values as well as $95 \%$ confidence intervals (in brackets) are indicated on the top of graphs.

Figure 2. Reversibility of TKI-mediated OCT3 activity inhibition.

HEK-OCT3 cells were first incubated in the absence or presence of $10 \mu \mathrm{M}$ TKIs for 5 min at $37^{\circ} \mathrm{C}$. After washing, cells were either used directly for OCT 3 activity measurement, performed as described in Materials and Methods, or were re-incubated in TKI-free medium for $3 \mathrm{~h}$ before OCT3 activity measurement. Data are expressed as percentages of OCT3 activity inhibition and are the means $\pm \mathrm{SD}$ of at least three independent experiments. $* * *, \mathrm{p}<0.05$ when compared to counterparts not subjected to a $3 \mathrm{~h}$ TKI-free post-incubation.

Figure 3. Trans-stimulation of OCT3 activity by TKIs.

HEK-OCT3 cells were first incubated in the absence (untreated) or presence of $1 \mathrm{mM}$ unlabeled $\mathrm{MPP}^{+}$or $30 \mu \mathrm{M}$ TKIs for $30 \mathrm{~min}$ at $37^{\circ} \mathrm{C}$. After washing with PBS, cells were next re-incubated with $6 \mathrm{nM}\left[{ }^{3} \mathrm{H}\right]-\mathrm{MPP}^{+}$for $5 \mathrm{~min}$ at $37{ }^{\circ} \mathrm{C}$. Intracellular accumulation of $\left[{ }^{3} \mathrm{H}\right]-\mathrm{MPP}^{+}$was finally determined by scintillation counting. Data were expressed as percentages of $\left[{ }^{3} \mathrm{H}\right]-\mathrm{MPP}^{+}$ accumulation found in control untreated cells, arbitrarily set at $100 \%$ and indicated by a dashed line on the graph; they are the means \pm SD of three independent assays. $* * *, p<0.001$ when compared to untreated cells.

Figure 4. Accumulation of TKIs in HEK-CTR and HEK-OCT3 cells.

HEK-CTR and HEK-OCT3 cells were incubated with $10 \mu \mathrm{M}$ TKIs or $10 \mu \mathrm{M}$ DiASP, in the absence or presence of $100 \mu \mathrm{M}$ corticosterone, for $5 \mathrm{~min}$ at $37{ }^{\circ} \mathrm{C}$. After washing with PBS, intracellular accumulations of TKIs and DiASP were determined by LC-MS/MS and spectrofluorimetry, respectively, and normalized to protein content. Data are the means \pm SD of 
four independent assays. $* * *, p<0.001$; NS, not statistically significant. FAU, fluorescence arbitrary unit. 


\begin{tabular}{|c|c|c|}
\hline TKI & Main targeted kinase & $\begin{array}{c}\text { \% inhibition of OCT3 activity } \\
(\text { Mean } \pm \text { SD) }\end{array}$ \\
\hline Abemaciclib & CDK4/6 & $69.4 \pm 7.1 * * *$ \\
\hline Acalabrutinib & BTK & $88.6 \pm 6.3 * * *$ \\
\hline Afatinib & EGFR & $76.3 \pm 9.3 * * *$ \\
\hline Alectinib & ALK & $11.3 \pm 16.7$ \\
\hline Brigatinib & ALK & $103.3 \pm 7.7 * * *$ \\
\hline Cabozantinib & VEGFR2, c-Met, c-Kit, Axl and Flt3 & $22.8 \pm 29.8$ \\
\hline Ceritinib & ALK & $99.9 \pm 7.9 * * *$ \\
\hline Crizotinib & ALK & $99.8 \pm 4.3 * * *$ \\
\hline Dacomitinib & EGFR & $71.4 \pm 13.0 * * *$ \\
\hline Entrectinib & Pan-TRK, ROS1, and ALK & $77.4 \pm 10.8 * * *$ \\
\hline Ibrutinib & BTK & $75.1 \pm 14.2 * * *$ \\
\hline Itacitinib & JAK1 & $0.0 \pm 10.1$ \\
\hline Lapatinib & ErbB-2 and EGFR & $1.7 \pm 7.3$ \\
\hline Lenvatinib & $\begin{array}{c}\text { VEGFR1-3, FGFR1-4, PDGFR, Kit, } \\
\text { and Ret }\end{array}$ & $67.0 \pm 11.3 * * *$ \\
\hline Lorlatinib & ROS1 and ALK & $41.0 \pm 3.6 * * *$ \\
\hline Neratinib & ErbB-2 and EGFR & $39.5 \pm 7.6 * * *$ \\
\hline Nintedanib & VEGFR, FGFR and PDGFR & $47.6 \pm 12.4 * * *$ \\
\hline Osimertinib & EGFR & $48.5 \pm 19.8 * * *$ \\
\hline Pacritinib & JAK2 and Flt3 & $90.0 \pm 5.8 * * *$ \\
\hline Ponatinib & $\mathrm{CDK} 4 / 6$ & $79.2 \pm 7.1 * * *$ \\
\hline Regorafenib & $\begin{array}{c}\text { VEGFR1/2/3, PDGFR } \beta \text {, Kit, Ret and } \\
\text { Raf-1 }\end{array}$ & $29.0 \pm 24.9 *$ \\
\hline Ribociclib & CDK4/6 & $74.3 \pm 7.3 * * *$ \\
\hline Ruxolitinib & JAKs & $47.6 \pm 11.4 * * *$ \\
\hline Tofacitinib & JAKs & $46.2 \pm 15.0 * * *$ \\
\hline Vemurafenib & B-Raf & $16.0 \pm 3.1$ \\
\hline
\end{tabular}

Table 1. Effect of $10 \mu \mathrm{M}$ TKIs on OCT3 activity in HEK-OCT3 cells.

ALK, anaplastic lymphoma kinase; BTK, Bruton's tyrosine kinase; c-Met, hepatocyte growth factor receptor (HGFR); CDK, cyclin-dependent kinase; EFGR, epidermal growth factor receptor (also known as ErbB-1 or HER1); ErbB-2, human epidermal growth factor receptor-2 (also known as HER2); FGFR, fibroblast growth factor receptor; Flt3, Fms-like tyrosine kinase 3; JAK, Janus kinase ; PDGFR, platelet-derived growth factor; 
TRK, tropomyosin receptor kinase (also known as NTRK, neurotrophic tyrosine receptor kinase); VEGFR, vascular endothelial growth factor.

$*, \mathrm{p}<0.05$ and $* * *, \mathrm{p}<0.001$, when compared to control cells not exposed to TKIs. 
Table 2. List of TKI molecular descriptors correlated with OCT3 activity inhibition by $10 \mu \mathrm{M}$ TKIs.

\begin{tabular}{|c|c|c|c|}
\hline \multicolumn{2}{|r|}{ Molecular descriptor } & \multicolumn{2}{|c|}{ Correlation with OCT3 inhibition \% } \\
\hline Block & Name & $\begin{array}{c}\text { Pearson } \\
\text { coefficient (r) }\end{array}$ & $\begin{array}{l}\text { Significance } \\
\text { (p value) }\end{array}$ \\
\hline \multirow{5}{*}{$\begin{array}{l}\text { Constitutional indices } \\
\qquad(\mathrm{n}=47)^{\mathrm{a}}\end{array}$} & $\begin{array}{l}\text { Mean atomic van der Waals volume } \\
\text { (scaled on Carbon atom) (Mv) }\end{array}$ & -0.4682 & 0.018 \\
\hline & $\begin{array}{c}\text { mean atomic Sanderson electronegativity } \\
\text { (scaled on Carbon atom) (Me) }\end{array}$ & -0.4255 & 0.034 \\
\hline & Percentage of $\mathrm{H}$ atoms $(\mathrm{H} \%)$ & 0.4886 & 0.013 \\
\hline & Percentage of $\mathrm{C}$ atoms $(\mathrm{C} \%)$ & -0.4501 & 0.024 \\
\hline & $\begin{array}{l}\text { mean absolute charge (charge polarization) } \\
\text { (Qmean) }\end{array}$ & -0.4135 & 0.040 \\
\hline \multirow{2}{*}{$\begin{array}{l}\text { Charge descriptors } \\
\qquad(\mathrm{n}=16)\end{array}$} & percentage of cationic forms at $\mathrm{pH}=7.4$ & 0.4946 & 0.012 \\
\hline & Unsaturation index (Ui) & -0.4184 & 0.037 \\
\hline $\begin{array}{l}\text { Molecular properties } \\
\qquad(\mathrm{n}=20)\end{array}$ & & & \\
\hline
\end{tabular}

${ }^{a} \mathrm{n}=$ total number of molecular descriptors/block included in the study; these molecular descriptors were given by Dragon 7.0 software, excepted the \% of cationic form at $\mathrm{pH}=7.4$ for the block "Charges descriptors", which was determined using MarvinSketch 20.19.0 software. 
Table 3: Prediction of in vivo OCT3 inhibition by TKIs.

\begin{tabular}{|c|c|c|c|c|c|c|c|}
\hline Drug & $\mathbf{C}_{\mathbf{m a x}}$ & $\mathbf{F}_{\mathbf{u}}$ & $\begin{array}{c}\mathbf{I}_{\text {max, }} \\
(\mathrm{nM})\end{array}$ & $\begin{array}{c}\mathbf{I C}_{\mathbf{5 0}} \\
(\mathrm{nM})\end{array}$ & $\begin{array}{c}\text { Ratio } \\
\mathbf{I}_{\mathbf{m a x}, \mathbf{u}} / \mathbf{I C}_{\mathbf{5 0}}\end{array}$ & $\begin{array}{c}\text { Predicted in vivo } \\
\text { inhibition }\end{array}$ & Reference \\
\hline Acalabrutinib & $1209 \mathrm{nM}$ & 0.025 & 30.2 & 1841.0 & 0.02 & No & {$[41]$} \\
\hline Brigatinib & $2482 \mathrm{nM}$ & 0.340 & 844.0 & 41.0 & 20.59 & Yes & {$[29]$} \\
\hline Ceritinib & $1800 \mathrm{nM}$ & 0.028 & 50.4 & 28.2 & 1.79 & Yes & {$[42]$} \\
\hline Crizotinib & $1061 \mathrm{nM}$ & 0.093 & 98.7 & 106.1 & 0.93 & Yes & {$[43]$} \\
\hline Pacritinib & $22500 \mathrm{nM}$ & 0.011 & 247.5 & 854.9 & 0.26 & Yes & {$[44]$} \\
\hline
\end{tabular}

$\mathrm{C}_{\max }$, maximum serum concentration; $\mathrm{F}_{\mathrm{u}}$, unbound fraction; $\mathrm{I}_{\max , \mathrm{u}}$, maximum unbound serum concentration. An in vivo inhibition can be predicted if the ratio $\mathrm{I}_{\max , \mathrm{u}} / \mathrm{IC}_{50}>0.1$ according to the US FDA [12]. 

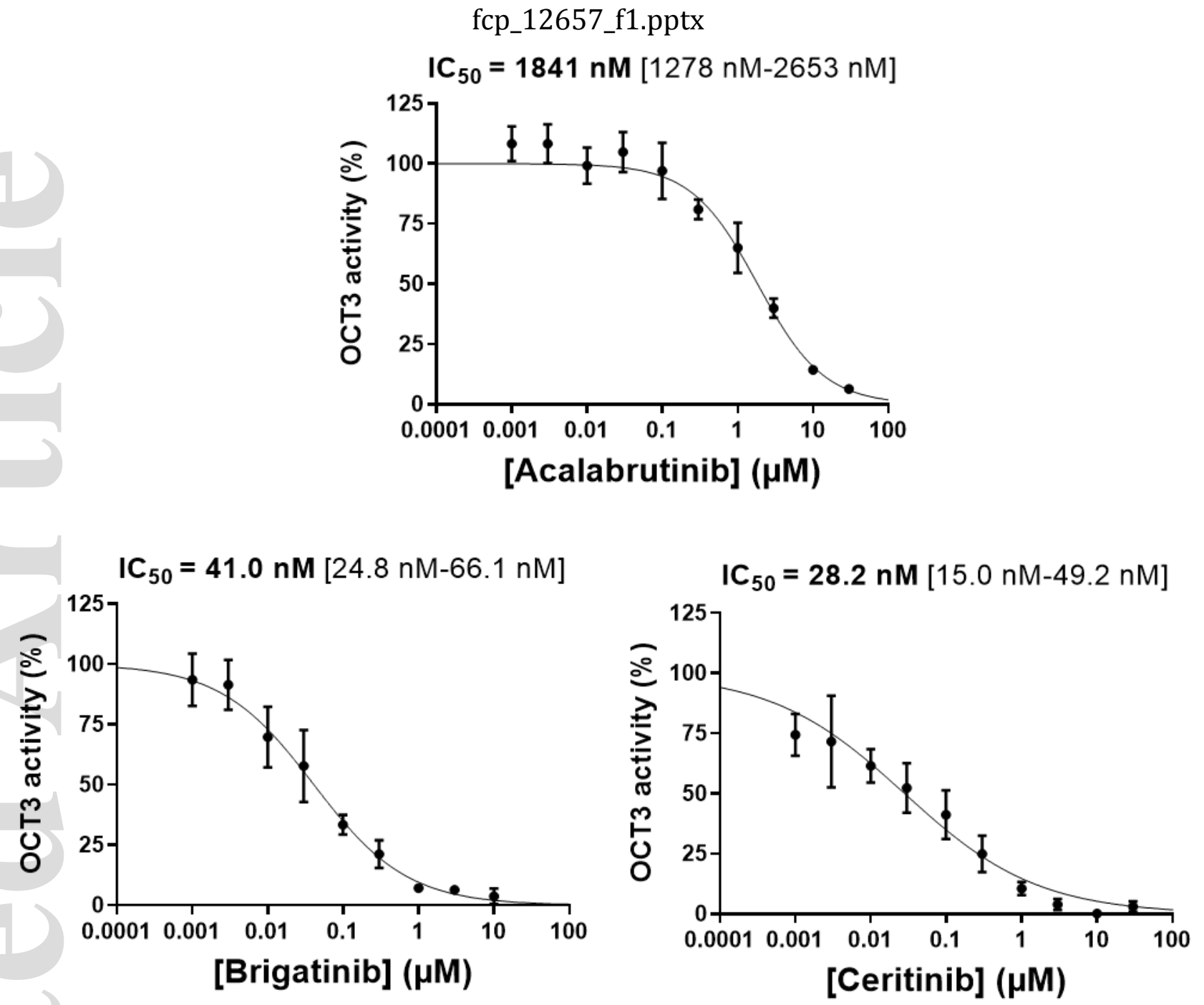

$I_{50}=106.1 \mathrm{nM}[72.4 \mathrm{nM}-154.2 \mathrm{nM}]$
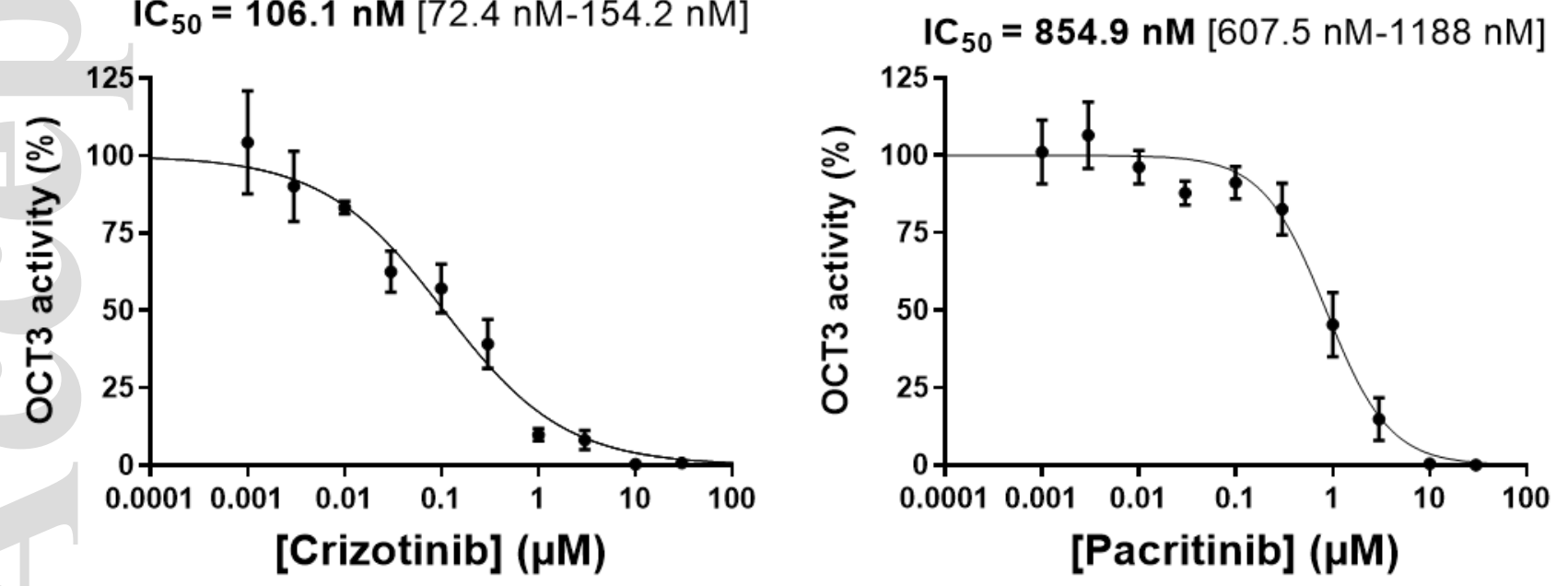

This article is protected by copyrigguffer rithts reserved 
- Without a TKI-free post-incubation period

$\square$ With a $3 \mathrm{~h}$ TKI-free post-incubation period

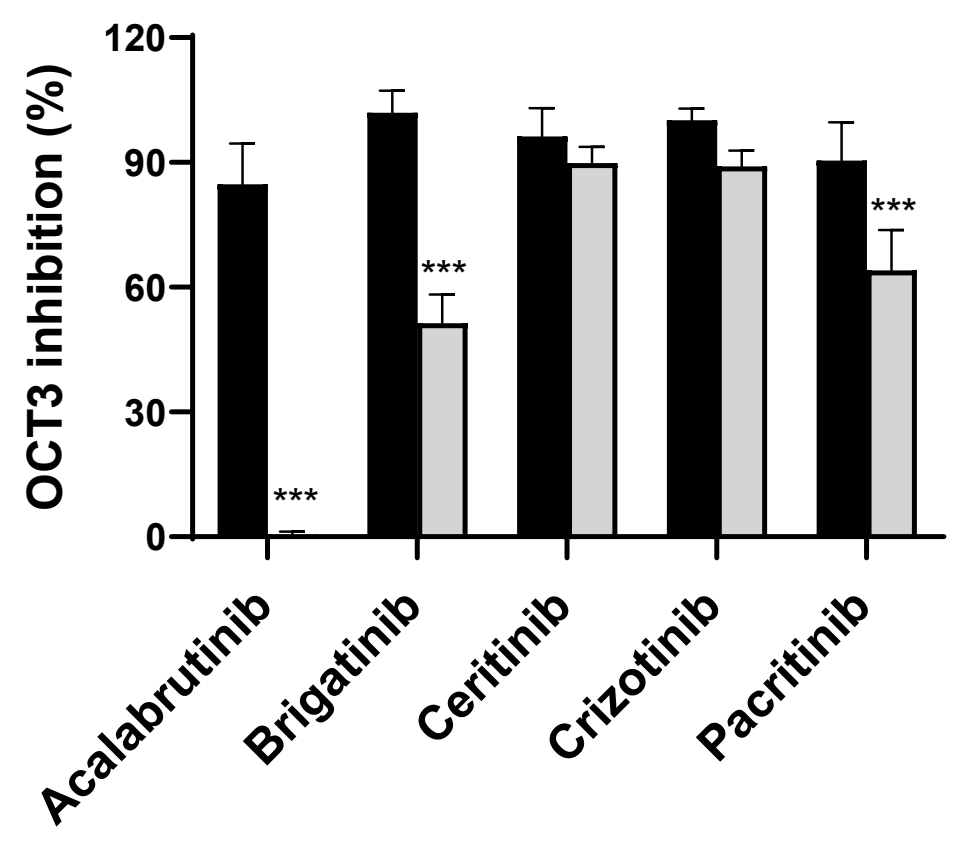

Figure 2 


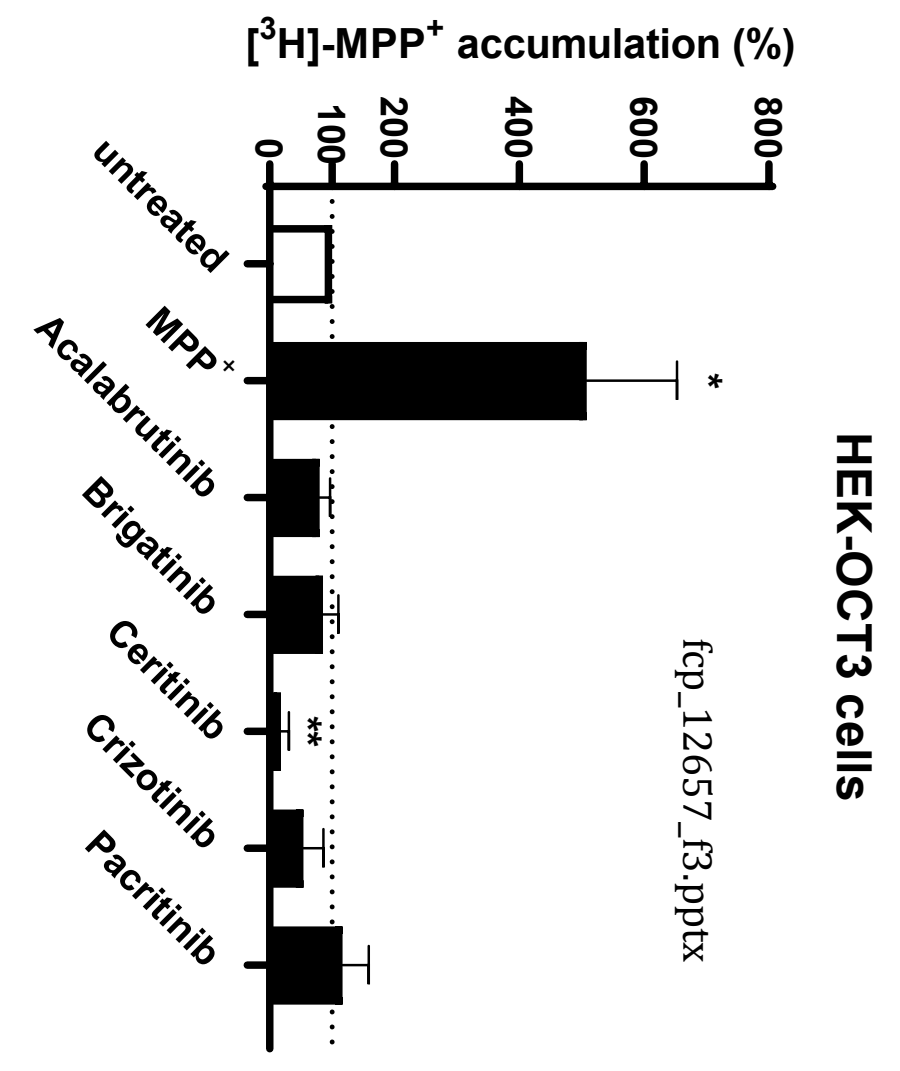




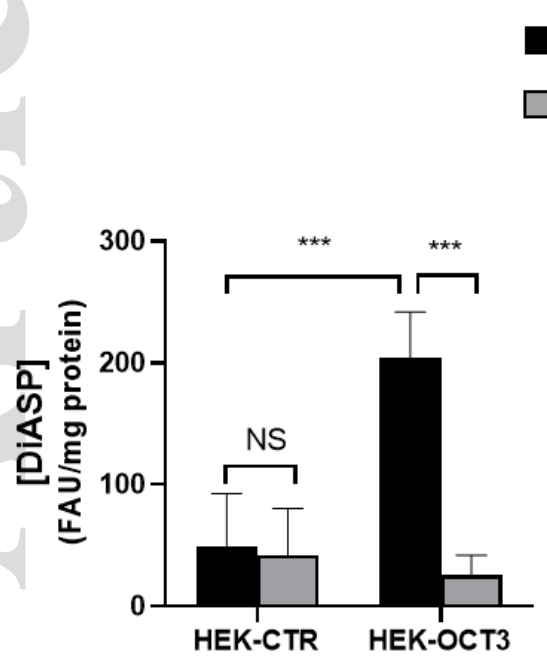

- Corticosterone

+ Corticosterone $(100 \mu \mathrm{M})$
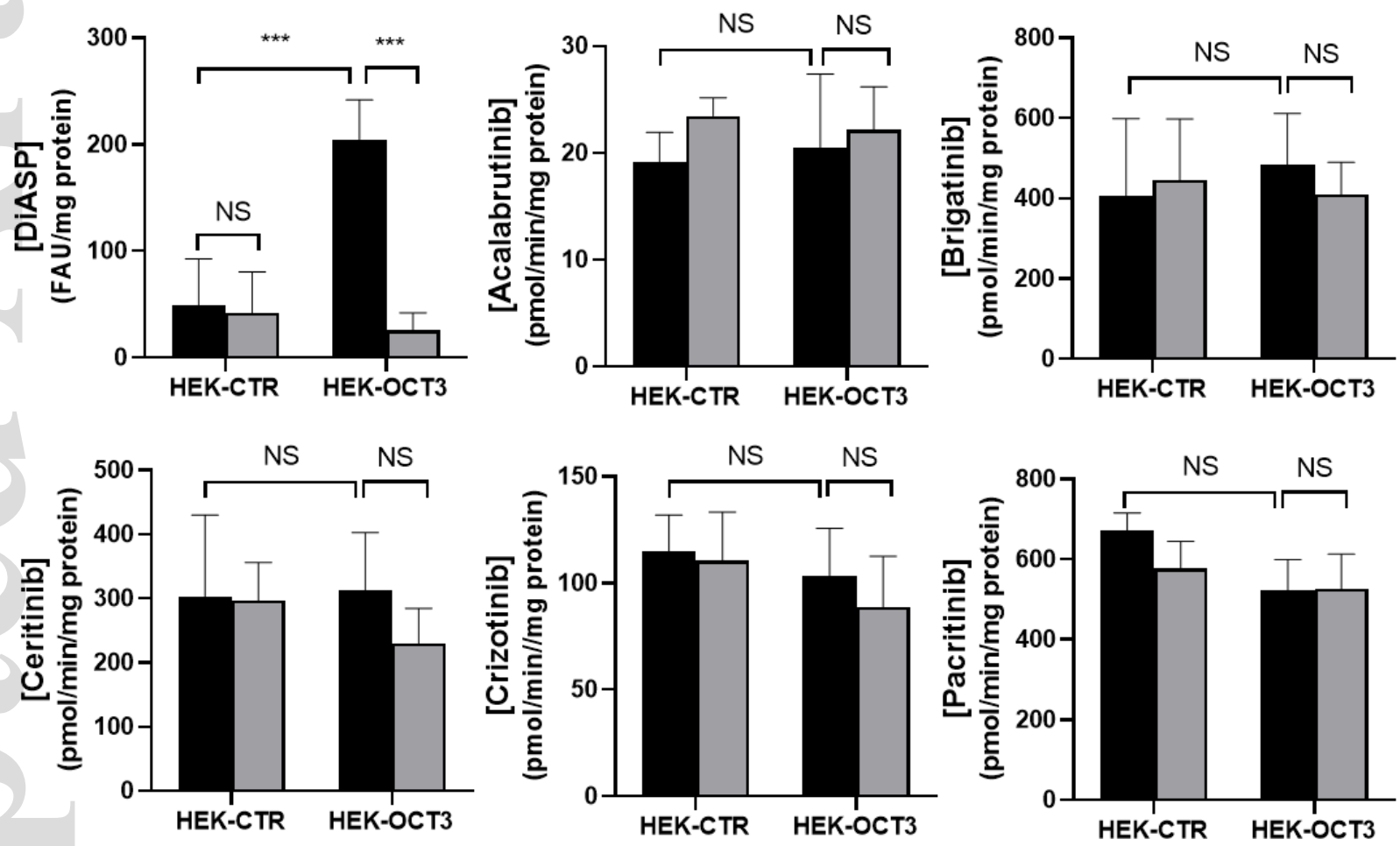

Figure 4 